\title{
Cardiac Surgery in Pregnant Women
}

\author{
Edmo Atique Gabriel, Camila Alcalde Mazza and Marina Alves Jacintho de Mello* \\ Union of the Colleges of the Great Lakes- UNILAGO, Brazil \\ ${ }^{\star}$ Corresponding Author: Marina Alves Jacintho de Mello, Union of the Colleges of the Great Lakes- UNILAGO, Brazil; E-mail: marinajmello@hotmail.com
}

Received: March 04, 2020; Accepted: March 09, 2020; Published: April 12, 2020

\begin{abstract}
Summary
The need for cardiac surgery during pregnancy is rare. Only $1 \%$ to $4 \%$ of pregnancies are complicated by maternal heart disease and most of them can be treated with medical therapy and lifestyle changes. Occasionally, whether due to the natural progression of underlying heart disease or precipitated by cardiovascular changes in pregnancy, cardiac surgical therapy should be considered. Cardiac surgery is inherently dangerous for both mother and fetus with mortality rates close to $10 \%$ and $30 \%$, respectively. For some conditions, percutaneous cardiac intervention offers effective therapy with much less risk for the mother and her fetus. For others, cardiac surgery, including procedures that require the use of cardiopulmonary bypass, should be considered to save the mother's life. Given the extreme risks to the fetus, if the patient is in the third trimester, serious consideration should be given to pre-operative delivery involving cardiopulmonary bypass. At earlier gestational ages, when this is not feasible, modifications to the infusion protocol, including higher flow rates, normothermic perfusion, pulsatile flow, and the use of intraoperative monitoring of the external fetal heartbeat should be considered.
\end{abstract}

Keywords: Cardiac surgical procedures, Cardiopulmonary bypass, Cardiovascular, Surgery, Complications of pregnancy, Heart defects congenital, Pregnancy

\section{Introduction}

Cardiovascular adaptations during pregnancy are usually well tolerated in healthy women. However, $2 \%$ to $4 \%$ of women of childbearing age have some degree of concomitant heart disease, and these changes may compromise cardiac function. Of these, some who do not respond to medical treatment may require surgical correction. In this scenario, the maternal mortality rate improved to levels similar to non-pregnant women. However, the fetal mortality rate remains high (up to 33\%). Factors contributing to the high rates of fetal mortality include the timing of the operation, the urgency of the operation, and the fetal / fetoplacental response to cardiopulmonary bypass. Modulation of the fetoplacental response to cardiopulmonary bypass may prevent placental dysfunction and sustained uterine contractions that underlie fetal hypoxia and acidosis. In this article, we reviewed the cardiovascular adaptations to pregnancy and the pathophysiological effects of cardiopulmonary bypass on the mother, fetus and fetoplacental unit, and talked about whether manipulating these responses can help improve fetal outcome. Finally, approaches to perfusion management and cardiac surgical techniques without extracorporeal circulation in pregnancy were made.

Khandelwal et al [1] points out that approximately $2 \%$ to $4 \%$ of women of childbearing age have concomitant heart disease. According to Abbas [2], Congenital Heart Disease (CHD) is responsible for most structural heart diseases that affect women of childbearing age. Abbas [2] also points out that the acquired heart disease observed during pregnancy is mainly valvular in nature, usually a consequence of rheumatic fever. Although rheumatic fever is decreasing in developed countries, it remains a serious problem in the developing world. Immigrants also form a high-risk population, especially those who are unaware of the risks inherent in heart disease during pregnancy or unaware of the presence of any heart disease. In this regard, mitral stenosis is the most commonly found lesion. Abbas [2] further states that although its incidence is declining, aortic valve disease is less common: aortic incompetence is usually a consequence of endocarditis ( 1 in 8,000 pregnancies) or aortic dissection, in which case there may be tissue disease. underlying connective tissue such as Marfan syndrome. Thus, significant aortic stenosis is uncommon in this age group. Parry [3] points out that ischemic events during pregnancy are rare. The incidence of myocardial infarction is approximately 1 in 10,000 pregnancies. Mabie [4] states that infarction is usually secondary to underlying coronary artery disease, although spontaneous coronary artery dissection appears to be more common during pregnancy and accounts for $30 \%$ of all myocardial infarctions seen in pregnancy.

\section{Maternal and Fetal Predictors}

Siu [5] highlights that heart disease in the mother is the leading cause of maternal death during pregnancy. Of these patients, $25 \%$ have congenital heart disease. In a large prospective multicenter study on pregnancy outcomes among women with heart disease, adverse cardiovascular events were observed in $13 \%$ of patients. Independent predictors of maternal cardiac complications included previous cardiac events, functional class III / IV, left heart obstruction, and left ventricular systolic dysfunction. Neonatal complications were observed in $20 \%$ and were associated with functional class or poor cyanosis, left heart obstruction or smoking. Klairy [6] says that a recent prospective observational study in pregnant patients with congenital heart disease found that both cardiac complication and neonatal complication rates were considerable in these women. In 
mothers, right subpulmonary ventricular systolic dysfunction and severe pulmonary regurgitation were predictors of an adverse fetal outcome

Drenthen [7], in his bibliographic review, describes that the results of 2,491 pregnancies among women with structural heart disease (congenital heart disease), were observed substantial cardiac complications in $11 \%$ of pregnancies. Obstetric complications do not appear to be more prevalent except for hypertensive disorders and thromboembolic events. In patients with complex CHD, rates of preterm delivery ranged from $22 \%$ to $65 \%$, and neonates were lower than normal for gestational age.

\section{Maternal Cardiovascular Changes During Pregnancy}

In the presence of maternal heart disease, circulatory changes in pregnancy may result in decompensation and death of the mother or fetus. Pregnancy produces changes in the cardiovascular system that have profound implications for heart surgery. Cardiac output increases markedly by the end of the first trimester, followed by a more gradual increase of $30 \%$ to $40 \%$ above baseline until the third trimester partly due to an increase in stroke volume and heart rate. In most patients, this hyperdynamic situation results in mild midsystolic murmur [8]. Diastolic murmurs may be normal, but deserve further investigation. At the end of pregnancy, compression of the lower uterine vena cava in the supine position decreases venous return and reduces cardiac output. Relief of vena cava compression is easily achieved by positioning the patient in the left lateral position. Systemic and pulmonary vascular resistance falls due to the effects of circulating prostaglandins in addition to other hormones and the poor resistance of the placental circulation. This lowers blood pressure during the first half of pregnancy, but pressure tends to increase in the second half [9].

Blood volume increases with a concomitant increase in plasma volume and red blood cell volume. Plasma volume expands by approximately $40 \%$ at term, when red cell mass increases by about $20 \%$. Consequently, there is a drop in hematocrit and blood viscosity [10]. Hemoglobin's oxygen carrying capacity is increased by a right shift on the oxygen dissociation curve. Pregnancy induces a procoagulant state with a 2-fold increase in fibrinogen level and an increase in factors V, VII, VIII, IX, and X, which has teleological advantage as it helps in hemostasis and reduces blood loss. during childbirth. In addition, this state ensures the optimal supply of oxygen and nutrients to the mother and fetus

\section{Responses to Cardiopulmonary Bypass}

\section{Maternal}

As the circulation of pregnant women has already undergone significant changes, the additional effect of Cardiopulmonary Bypass $(\mathrm{CPB})$ induces a non-physiological hemodynamic state that may adversely affect the mother during cardiac surgery. This effect is amplified by simultaneous changes in the cellular and protein components of the blood. Hemodilution and changes in coagulation, complement activation, release of vasoactive substances by leukocytes, gas embolism and hypotension during $\mathrm{CPB}$ are further added to the deleterious effect. However, these effects are relatively well tolerated by the mother, as the maternal mortality rate associated with $\mathrm{CPB}$ in pregnant women is similar to that of non-pregnant women undergoing CPB-like cardiac procedures [3].

\section{Uterine}

Sustained uterine contractions during cardiac surgery and CPB are accepted as the most important cause of fetal death. Sustained uterine contractions reduce uterine blood flow and interventional perfusion, resulting in fetoplacental insufficiency and subsequent fetal hypoxia. Cardiopulmonary bypass has other potentially deleterious effects on the uterus during pregnancy. Both cooling and reheating phases are associated with increased sustained uterine contractions. This observation is supported by the fact that there is a noticeably higher fetal mortality rate with hypothermic CPB than with normothermic $\mathrm{CPB}$ [3]. Uterine muscle excitability is probably increased by hormonal dilution, especially by progesterone dilution. Postoperative progesterone administration successfully eliminated preterm labor.

\section{Fetoplacental shunt}

Experimental studies of fetal CPB provided much information on the fetoplacental response, which could shape future management of $\mathrm{CPB}$ in pregnant women. Studies in sheep have repeatedly shown that standard non-pulsatile flow perfusion rapidly causes severe placental dysfunction dominated by a strong vasoconstrictor reaction. Vasodilators have been used with some success to overcome this increase in placental vascular resistance, producing improvement in both placental blood flow and acidosis [11]. A study of the human placenta under physiological conditions reveals that an active fetal renin-angiotensin system can modulate placental perfusion in vivo. Endothelial dysfunction is a cause or an effect of excessive renin-angiotensin activity that has yet to be resolved. Lactate levels during $\mathrm{CPB}$ pulsatile flow were stable, while a continuous increase is observed with non-pulsatile CPB. Manipulation of the fetal lamb during $\mathrm{CPB}$ has been shown to produce significant lactic acidosis; this was considered as a result of metabolic debt of fetal stress, and anesthesia. Since lactate release into the maternal circulation was similar between the beginning and the end of $\mathrm{CPB}$, the increase in fetal lactate probably originated from within the fetus. The placenta plays an important role in regulating circulating lactate levels under hypoxic conditions, thus allowing the fetus to maintain stable lactate levels. However, a reduction in placental perfusion prevents lactate clearance in the fetal circulation [11].

\section{Fetal}

The fetal mortality rate during maternal cardiac surgery with $\mathrm{CPB}$ ranges from $16 \%$ to $33 \%$. Increased gestational age and increased hypothermia are factors known to increase fetal morbidity during $\mathrm{CPB}$. Unfortunately, little experimental evidence is available on the fetal response to maternal $\mathrm{CPB}$. Fetal cardiac monitoring usually shows that the onset of $\mathrm{CPB}$ is bradycardia, which in most cases reverts to sinus rhythm immediately after CPB cessation [13]. Alternatively, an initial tachycardia may occur, accompanied by an 
increase in blood pressure. Fetal bradycardia observed after the onset of $\mathrm{CPB}$ is corrected by increased blood flow and the restoration of maternal circulation upon CPB discontinuation. The mechanism of this bradycardic response is unknown, but several causes have been postulated, including fetoplacental dysfunction, fetal hypoxia and acidosis, maternal hypothermia, and drugs that cross the placental barrier, such as $\beta$-adrenergic blockers [14]. Fetal hypoxia during CPB may be a consequence of hemodilution, as hemodilution reduces the oxygen content in the maternal blood. Other causes of fetal hypoxia include reduced uterine perfusion pressure and increased uterine vascular resistance [14] Because placental blood vessels are maximally dilated during pregnancy, uterine blood flow is not self-regulating but directly depends on maternal mean arterial pressure and uterine vascular resistance.

Decreased maternal blood pressure may result in fetal bradycardia shortly before the onset of CPB. Maternal hypotension soon after cardiopulmonary bypass is caused by decreased systemic vascular resistance caused by reduced flow rate, hemodilution, and release of vasoactive substances, which may result in a significant reduction in placental perfusion. Cardiac fetal decelerations observed during CPB are probably caused by reduced blood flow to the interventional spaces and the resulting fetal hypoxia. Factors such as non-pulsatile flow, uterine arteriovenous bypass, and obstruction of venous drainage by cannulation of the inferior vena cava, particulate and gas emboli, and spasm of the uterine artery may reduce placental circulation and lead to fetal hypoxia. When CPB is prolonged, there is a significant risk that the fetus will develop a prolonged bradycardic response. Changes in fetal heart rate may be observed even when maternal circulation, acid-base balance and perfusion pressure are stable. Therefore, it has been postulated that these changes are related to the narcotic effect of drugs used during anesthesia. Vasoconstrictors may reduce uteroplacental flow (direct evidence of this is lacking) and should be avoided, although phenylephrine and ephedrine are considered safe during pregnancy.

\section{Surgical Issue}

The principles for the management of pregnant patients undergoing cardiac surgery with $\mathrm{CPB}$ are similar to those of pregnant women undergoing surgical intervention. These include: attention to maternal well-being, prevention of teratogenic drugs, prevention of intrauterine hypoxia and prevention of premature labor. In addition, strong consideration should be given to the administration of maternal corticosteroids to initiate endothelial membrane stability and fetal lung maturation, which can substantially improve fetal outcome if delivery occurs after CPB. In summary, the main concerns in optimal management of pregnant patients undergoing $\mathrm{CPB}$ are temperature control, perfusion pressure, and the nature of bypass flow. Current evidence favors the maintenance of normothermic $\mathrm{CPB}$, avoiding the use of vasoconstrictors (which may have a profound effect on the placental unit) and maintaining high hematocrit rates and high blood flow rates. Fetal hypoperfusion and hypoxia may also be alleviated by the use of pulsatile perfusion. Other adjuncts, such as the use of arterial line filters or leukocyte depletion filtration, have not been evaluated in the specific context of pregnant patients [15].

\section{Extracorporeal Circulation}

Aggarwal and coauthors [16] reported that closed mitral valvotomy offers excellent results, comparable to non-surgical treatments; It is still the procedure of choice in certain parts of the world. Myocardial revascularization without cardiopulmonary bypass is a safe and accepted technique for coronary revascularization; However, its role in pregnancy needs further evaluation. The current medical literature contains only 1 documented case of myocardial revascularization during pregnancy - that of a 32-year-old woman at the 22nd week of gestation who had a spontaneous dissection of the left anterior descending artery and subsequently delivered a healthy baby at term. Hemodynamic instability during unsupported myocardial revascularization (CABG) surgery - involving a decrease in mean systemic blood pressure and an increase in mean pulmonary pressure during distal anastomosis construction and heart manipulation to gain access to the lateral and posterior branches - may not be well tolerated by pregnant patients and could cause significant placental malfunction. However, if only one anterior target (such as the anterior descending coronary artery territory) is grafted, this can usually be accomplished with minimal hemodynamic compromise and avoid all risks inherent to $\mathrm{CPB}$, such as hemodilution, systemic inflammatory response to $\mathrm{CPB}$ and increased risk of bleeding [17].

To deepen our understanding of the placental and fetoplacental response to off-pump myocardial revascularization surgery, it is useful to look at how other vascular beds, such as splanchnic circulations, behave during off-pump coronary artery bypass grafting (CABG). If we hypothesize that splanchnic and fetoplacental circulations will respond similarly to hemodynamic insults during $\mathrm{CPB}$ myocardial revascularization surgery, much can be learned by observing splanchnic and gastrointestinal physiology during cardiac operations. L-lactate concentration has been significantly higher in the intestinal mucosa of patients undergoing myocardial revascularization with $\mathrm{CPB}$ than without $\mathrm{CPB}$ [17]. This supports the view that without $\mathrm{CPB}$ produces less dysfunction in these vascular beds than $\mathrm{CPB}$. When Fiore et al. [18] examined upper mesenteric blood flow during myocardial revascularization, they found that cardiac manipulation to gain access to the lower and lateral walls caused hemodynamic changes that resulted in significant mesenteric hypoperfusion. Such information can help us plan the approach to revascularization we want to perform in pregnant patients who develop spontaneous coronary artery dissection.

\section{Conclusion}

Spontaneous single vessel or two vessel dissections, particularly in the anterior descending territory or right coronary artery territory, are probably the best candidates for off-pump surgery: the use of $\mathrm{CPB}$ in these instances avoids manipulation of the heart to reach the posterior artery. and inferior, thus avoiding hemodynamic instability and its effects on fetoplacental circulation More observational data should be collected in the context of myocardial revascularization in pregnancy, with particular attention to responses. fetal and maternal cardiovascular diseases, before myocardial revascularization can be safely recommended as the ideal therapy for this challenging group of patients. 


\section{References}

1. Khandelwal M, Rasanen J, Ludormirski A, Addonizio P, Reece EA (2015) Avaliação da hemodinâmica fetal e uterina durante a circulação extracorpórea materna. Obstet Gynecol 88: 667-671.

2. Abbas AE, Lester SJ, Connolly H (2005) Gravidez e sistema cardiovascular. Int J Cardiol 98: 179-189.

3. Parry AJ, Westaby S (2015) Circulação cardiopulmonar durante a gravidez. Ann Thorac Surg 61: 1865-1869.

4. Mabie WC, Freire CM (2012) Dor súbita no peito e emergências cardíacas no paciente obstétrico. Obstet Gynecol Clin North Am 22: 19-37.

5. Siu SC, Sermer M, Colman JM, Alvarez AN, Mercier LA, et al. (2001) Estudo prospectivo multicêntrico dos resultados da gravidez em mulheres com doença cardíaca. Circulation 104: 515-521.

6. Khairy P, Ouyang DW, Fernandes SM, Lee-Parritz A, Economia KE, et al. (2006) Resultados da gravidez em mulheres com cardiopatia congênita. Circulation 113: $517-524$.

7. Drenthen W, Pieper PG, Roos-Hesselink JW, van Lottum WA, Voors AA, et al. (2007) Desfecho da gravidez em mulheres com cardiopatia congênita: uma revisão de literatura. J Am Coll Cardiol 49: 2303-2311.

8. Edmonds KD, Dewhurst J (1999) Em: livro de obstetrícia e ginecologia de Dewhurst para pós-graduados. 6a ed. Malden (MA): Ciência Blackwell.

9. Clark SL, Cotton DB, Lee W, Bispo C, Hill T, et al. (2009) Avaliação hemodinâmica central da gravidez a termo normal. Am J Obstet Gynecol 161: 1439-1442.

10. Pomini F, D Mercogliano, Cavalletti C, Caruso A, Pomini P (2015) Circulação cardiopulmonar na gravidez. Ann Thorac Surg 61: 259-268.

11. Vedrinne C, Tronc F, Martinot S, Robin J, Allevard AM, et al. (2000) Melhor preservação da função endotelial e diminuição da ativação da via renina-angiotensina fetal com o uso de fluxo pulsátil durante a derivação fetal experimental. $J$ Thorac Cardiovasc Surg 120: 770-777.

12. Sabik JF, Heinemann MK, Assad RS, Hanley FL (2011) Esteróides de altas doses impedem a disfunção placentária após o bypass cardíaco fetal. J Thorac Cardiovasc Surg 107: 116-125.

13. Ralston DH, Shnider SM, DeLorimier AA (2011) Efeitos da efedrina equipotent, metaraminol, mephentermine, e metoxamina no fluxo sanguíneo uterino na ovelha grávida. Anesthesiology 40: 354-370.

14. Lees MH, Herr RH, Hill JD, Morgan CL, Ochsner AJ 3, et al. (2010) Distribuição do fluxo sanguíneo sistêmico do macaco rhesus durante a circulação extracorpórea. J Thorac Cardiovasc Surg 61: 570-586.

15. Silberman S, D Fink, Berko RS, B Mendzelevski, Bitran D (2015) Cirurgia de revascularização miocárdica durante a gravidez. Eur J Cardiothorac Surg 10: 925-926.

16. Aggarwal N, Suri V, Goyal A, Malhotra S, Manoj R, et al. (2005) Valvotomia mitral fechada na gravidez e no trabalho de parto. Int J Gynaecol Obstet 88: 118-121.

17. Perner A, Jorgensen VL, Poulsen TD, Steinbruchel D, Larsen B e Andersen LW (2005) Concentrações aumentadas de L-lactato no lúmen retal em pacientes submetidos à circulação extracorpórea. Ir. J Anaesth 95: 764-768.

18. Fiore G, N Brienza, Cicala P, Tunzi P, N Marraudino, et al. (2006) Superior modificações do fluxo sanguíneo da artéria mesentérica durante a cirurgia coronária sem CEC. Ann Thorac Surg 82: 62-67.

19. Levy DL, Warriner RA 3a, Burgess GE 3a. (2010) Resposta fetal à circulação extracorpórea. Obstet Gynecol 56: 112-115. 